\title{
Why should I share knowledge with others? A review-based framework on events leading to knowledge hiding
}

Amitabh Anand ${ }^{1}$, Piera Centobelli ${ }^{2}$, Roberto Cerchione ${ }^{3}$

1. SKEMA Business School, Université Côte d'Azur, GREDEG, Valbonne, France

2. Department of Industrial Engineering, University of Naples Federico II, Naples, Italy

3. Department of Engineering, University of Naples Parthenope, Napoli, Italy

\begin{abstract}
Over the past few decades, research has shown that managing and sharing of employee knowledge is essential for effective organizational change, innovation and competitive advantage. Despite numerous efforts to encourage knowledge sharing within organizations, employees may not always be ready to share the knowledge attributed because of their personal beliefs or situational constraints leading to knowledge hiding. This article addresses a review of the literature, identifies and illustrates the present and the possible knowledge hiding $(\mathrm{KH})$ events that occur between employees within the organizations. Through propositions we found five $\mathrm{KH}$ events that already exist in the literature and propose three events that may occur in the future. The proposed framework can help organizations and managers to advance strategies like adopting organizational change, restructuring, or increasing effective knowledge sharing among employees. By presenting discussions and future implications, our study concludes with limitations.
\end{abstract}

Keywords: Knowledge sharing, knowledge hiding, knowledge hoarding, knowledge withholding

\section{Introduction}

For organizations to succeed and be competitive, they expect their employees to share their knowledge with co-workers (Khalid et al. 2018; Malik and Garg, 2017). Although organizations put in a lot of effort to foster knowledge-sharing activities among individuals (Wang and Noe, 2010), the success of such effort relies on the employee's willingness and intention to share 
knowledge (Reige, 2005) and on various events that occur in the organization (Butt and Ahmad, 2019). Gagne et al. (2019) assert that as knowledge is a valuable resource and knowledge sharing depends on individuals who decide with whom, when, and why to share, certain factors such as dispositional values, situational constraints and lack of organizational culture come into play to explain why people might not share knowledge, even when there are benefits and rewards (Lanke, 2018; Anand and Walsh, 2016; Mergel et al. 2008; Nugroho, 2018). Knowledge is one of the vital assets that employees use to raise their status in organizations, yet the same workers can hide it, to increase their importance and to become indispensable (Zhao et al. 2016; Anand and Walsh, 2016). Connelly et al. 2019 have furthered investigations into why individuals do not share knowledge and the different facets of this phenomenon.

Many scholars have investigated the enablers of knowledge sharing at both individual and organizational levels (Nugroho, 2018; Chennamaneni et al. 2012; Wang and Noe, 2010) and in recent years, many studies have appeared investigating the barriers to knowledge sharing (Connelly et al. 2012; Reige, 2005). These barriers, including ' knowledge hiding ' (e.g. by Connelly et al. 2012), ' knowledge hoarding ' (e.g. by Connelly et al. 2012; Webster et al. 2008), 'knowledge withholding' (e.g. by Kang, 2014) are described as acts demonstrated by individuals not to share knowledge. Additionally, there has been a growing interest in recent years in why individuals hide, withhold or hoard knowledge from others in organizational setups (Skerlavaj et al. 2018; Connelly et al. 2012; Lin and Huang, 2010; Haas and Park, 2010). Subsequently, the construct of knowledge hiding has received increasing attention from researchers and practitioners alike (Connelly et al. 2012; Cerne et al. 2014).

\subsection{Research Context: Knowledge Hiding (KH)}

Knowledge sharing (KS) is defined as "the extent to which knowledge is made available to others within the organization" and "involves some conscious action on the part of the individual who possesses the knowledge" (Ipe, 2003, p. 341). It also involves an employee sharing taskrelevant ideas, information and suggestions with colleagues, for positive organizational outcomes such as individual and team creativity (Dong et al. 2017). However, for numerous reasons, employees do not always share task relevant knowledge and on many occasions, they hide knowledge from others. Thus, knowledge hiding refers to the act of intentionally concealing specifically requested knowledge from another person (Connelly et al. 2012; Demirkasimoglu, 
2016; Pan et al. 2016). Some scholars have emphasised that KH is different from knowledge hoarding (Connelly et al. 2012; Bari et al. 2019) and that $\mathrm{KH}$ is merely the failure to share knowledge (Connelly et al. 2012). This may arise because people are not aware of others' need for the knowledge (Gagne et al. 2019). Thus, hiding can be voluntary, situational or could be influenced by internal and external motivational factors (Anand et al. 2019). Other scholars, on the other hand, use knowledge hiding as a synonym of knowledge hoarding (Evans et al. 2014) and knowledge withholding (Kang, 2014; Webster et al. 2008). Additionally, knowledge hiding and knowledge hoarding are the two concepts that are used most often to describe non-sharing behaviours (Holten et al. 2016). Other research has noted that knowledge hiding, and hoarding are barriers to knowledge sharing and can be characterized as knowledge-withholding behaviours (Webster et al. 2008). Thus, for context setting, we include knowledge hiding, knowledge hoarding and knowledge withholding as synonyms of all the behaviours where the knowledge provider may share little, or no knowledge only when requested by the knowledge seeker.

At the individual level, the view of Connelly et al. (2012, p. 65) of knowledge hiding is based on the notion that there should be a request from a knowledge seeker which is not fulfilled by the knowledge provider. On the other hand, knowledge sharing and hiding can happen at various levels, for instance Anand et al. (2019) suggest that an individual can share or hide his knowledge depending on his/her willingness and intention from one individual to another, from an individual to a group, from a group/organization to an individual, or from a group/organization to another group/organization. Furthermore, scholars have identified numerous factors (at an individual, group, or organizational level) that lead to hiding or hoarding of knowledge in organizations. For instance, at an individual level, such factors include job dissatisfaction, low motivation, harmed relationships, formalization, job insecurity and work/managerial abuse (Khalid et al. 2018; Bock et al. 2005; Lin and Huang 2010; Wang et al. 2014; Zhao et al. 2016). At a group level, factors may be group culture (Bogilović et al. 2017), group task group characteristics (Cerne et al. 2014), group trust (Connelly and Zweig, 2014), relational capital, (Gardiner, 2016), negative co-worker relationships (Nowlin et al. 2015) and at an organizational level, workplace incivility (Arshad and Ismail, 2018), organizational climate (Cerne et al. 2017), poor organizational culture (Muqadas et al. 2017; Nugroho, 2018; Anand and Jain, 2014), and rewards (Nowlin et al. 2015; Milne, 2007). 
$\mathrm{KH}$ is believed by some to be a positive act. For instance, Connelly et al. (2012) argue that KH is not harmful because it can be influenced due to prosocial motivation; for example, rationalized hiding can strengthen interpersonal relationships between hiders and targets (Connelly and Zweig, 2015). However, research emphasizes more on understanding the negative effects of KH and specifically on making organizations focus on the two major questions: Why do employees hide their knowledge? What can organizations do to limit KH in the workplace? (Xio and Cooke, 2018). Despite the consequences, managers have not achieved success in controlling knowledge hiding actions (Anand and Hassan, 2019) and we contribute to the ongoing discussions to KH by proposing various events that lead to KH. Previous research by Connelly et al (2019) proposed that individuals engage in three $\mathrm{KH}$ behaviours: 'playing dumb', i.e. pretending ignorance or completely ignoring the request for knowledge; 'evasive hiding', i.e. providing incomplete knowledge and/or promising a complete answer in the future with no intention of doing so; and 'rationalized hiding', i.e. offering justification for hiding knowledge by giving false reasons or blaming someone else. Previous researchers have called for more studies to identify the predictors of KH from different perspectives (Xia et al. 2019; Connelly et al. 2012).

We found that $\mathrm{KH}$ can occur beyond these three individual behaviours and that $\mathrm{KH}$ events and antecedents have not been thoroughly investigated from an event or scenario-based context. Understanding the present events that lead to future $\mathrm{KH}$ behaviour can help managers forecast $\mathrm{KH}$ events. The antecedents of $\mathrm{KH}$ are often complex to understand. For instance, various personal, interpersonal and organizational elements studied to predict knowledge hiding have not been comprehensively assessed (Semeric, 2019). Thus, starting from these three premises, the aim of the current paper is to examine the scientific literature to answer the following research questions:

1) what are the various events involving personal, interpersonal, and organizational factors that lead an individual to hide knowledge?

2) what are the possible future KH events, which need managerial attention?

Identifying these events may help managers and organizations undergo an organizational change to enhance effective $\mathrm{KS}$ activities and help them to predict possible $\mathrm{KH}$ issues. This paper is organised as follows: first, we review the literature around the core construct of knowledge hiding and then show the propositions of present events of $\mathrm{KH}$, followed by proposing future 
possible events of KH. Lastly, through discussion and implications we suggest future research directions before concluding.

\section{Methodology}

In this paper we performed a systematic review of the literature to find an answer to the research question stated in the previous section. To ensure the methodological transparency adopted in our research, we explicitly layout the detailed steps adopted to find and analyze the literature.

First, we first performed a systematic search of papers, using a list of diverse keywords to extract articles on the topic of 'knowledge hiding' Table 1).

Second, a keyword protocol query was applied (see table 1 below) first in Scopus database which gave us 55 articles. However, as all relevant journals are not indexed in Scopus, according to Ott and Michailova (2018) to make well-grounded recommendations for future research, the same keywords were used to collect papers from other major scientific databases, including ProQuest, EBSCO and Google Scholar and this gave us 12 hits.

Table 1. Material selection review protocol

\begin{tabular}{|l|l|}
\hline Key word protocol query & N. of Hits \\
\hline Keyword Protocol applied in Scopus & 55 \\
TITLE-ABS-KEY ('knowledge hid*' OR 'hiding knowledge' OR 'hoarding & \\
knowledge' OR 'knowledge hoarding' OR 'knowledge withholding' OR & \\
'withholding knowledge') AND (LIMIT-TO (DOCTYPE, 'ar') OR LIMIT-TO & \\
(DOCTYPE, 'ip')) AND (LIMIT-TO (SUBJAREA, 'BUSI')). & \\
\hline $\begin{array}{l}\text { Keyword Protocol applied in Other databases (Google Scholar, Proquest, } \\
\text { EBSCO etc.) knowledge hiding' OR 'hiding knowledge' OR 'hoarding } \\
\text { knowledge' OR 'knowledge hoarding' OR 'knowledge withholding' OR } \\
\text { 'withholding knowledge' }\end{array}$ & \\
\hline
\end{tabular}

Third, from the articles obtained from Scopus and other databases we checked for and excluded any overlaps. This gave us the final count of 66 papers. From this dataset we successively applied the following steps to define the final sample of papers to be analysed: 
a) only articles from journals, conference papers and book chapters were selected, excluding editorials.

b) only articles that explicitly address the concept of knowledge hiding, knowledge hoarding, knowledge withholding in their title, abstract or in the keywords were included in the final sample;

c) finally, to select and deselect the articles from both Scopus and other database searches, the authors first, read the title and abstract of the paper. After studying the abstracts, we ensured that the paper exclusively addresses one of the keywords (knowledge hiding, hoarding and withholding) in at least one of the contexts, e.g. individual, dyadic, group, organization or theoretical were included. After careful review of the 66 articles, 52 were selected for analysis.

Fourth, we coded the selected articles in table format and classified their contents into the following categories and subcategories. We decided to 1) read the all the abstracts of the articles and synthesize the data through logical order based on common parameters. For instance, knowledge hiding, hoarding and withholding antecedents, consequences, level of investigation (individual, dyadic, group and organizational) etc. This allowed us to provide meaningful interpretation and to propose the various present and future events of KH. (Please see appendix 1 for the list of articles selected from Scopus and other databases).

Fifth, we interpreted our results using systematic reviews concerned with synthesis (Snilstveit $e t$ al. 2012). We adopted the review approach of synthesis and narrative overview proposed by Green et al. (2006). Synthesis is a systematic approach for synthesizing varied literature through narratives and summary that includes diverse data types (Bruce et al. 2016) and literature retrieved from database searches, hand searches, and authoritative texts (Green et al. 2006; Ferrari, 2015).

\section{Findings}

To understand $\mathrm{KH}$ behaviour for context setting, we argue that $\mathrm{KH}$ does not necessarily occur only when knowledge is requested (as suggested by Connelly et al, 2012, p. 650). Different 
events may lead to KH even when knowledge is not requested (Evans et al. 2015, p. 495) and in the next section we provide some events where such behaviour can occur among individuals.

\subsection{Events leading to KH behaviours}

In this section, based on the various constructs identified in the literature, we provide a coherent explanation of the events that lead to $\mathrm{KH}$ behaviours. Although the literature is dominated by the three infamous events that lead to KH as explained by Connelly et al. (2012) we identify several events that go beyond these events and still lead to $\mathrm{KH}$.

Situational constraints (leading to unintentional hiding): Lack of time, busy work engagements and workplace situations that are not convenient or comfortable to share knowledge, may result in $\mathrm{KH}$ when a seeker requests the knowledge from the provider. Skerlavaj (2018) through empirical study found that the antecedent, perceived time pressure, is positively related to knowledge hiding and employees who perceive greater time pressure hide knowledge only when they are low in prosocial motivation. These situational constraints do not necessarily make the provider hide knowledge intentionally, but rather unintentionally due to constraints. For example, according to Connelly et al. (2012), rationalized hiding happens when the knowledge hider presents a justification for not sharing the knowledge but may blame another party or situation. This hiding behaviour may lead to perceived negative emotions on the seeker's part if no explanation is provided and behaviour is subsequently amended when the situation evolves. Thus, this implies that there is an intention to hide knowledge. We argue, however, that knowledge hiding may not be deliberately intentional; it may be driven by situations where a knowledge provider may not be able to share knowledge at that moment but may share knowledge later. For example, "Hey you came the other time asking something from me. I was busy and totally forgot. Maybe we can talk about it now"

Proposition 1: Knowledge hiding is not always intentional but can be driven by situational constraints

Competition and performance (leading to motive hiding): When individuals need to survive at the workplace, the only way to retain one's job is through performance. A climate fostering competition (Nowlin et al. 2015) may lead to knowledge hoarding and performance in an organization prompts knowledge hiding (Rhee and Choi, 2017; Zhu et al. 2019; Xiong et al. 
2019). When one's job is at stake, when increased competition for performance may lead to job insecurity, this can motivate an individual to hide knowledge (Reige, 2005). Fearing threats, individuals may be more likely to keep and upgrade their knowledge, before any crisis occurs and abstain from sharing their experiences, knowledge and resources (Samerci, 2018). KH can occur among employees in a competitive workplace and, in order to increase their performance, they engage in KH behaviour (Peng, 2013; Singh, 2019). Pfeffer (1981) asserted that a colleague who perceives competition with a co-worker in a workplace usually hides knowledge. This loop of protecting individual knowledge due to competition can lead to territoriality (Kang, 2014). Furthermore, hoarding knowledge can increase performance and can also be used to impress superiors (Muqadas et al. 2017). In addition, to increase individual performance, employees hide knowledge from peers in the team (Fong et al. 2018), which reduces group performance (Cerne et al. 2014). Jha and Varkkey (2018) identified that competitive work environment and perceived career insecurity can lead to $\mathrm{KH}$.

Proposition 2: Workplace competition and performance create a motive for people to hide knowledge

\section{Psychological knowledge ownership (leading to controlled hiding)}

According to the theory of psychological ownership, employees may develop a feeling of ownership when they invest a large amount of time, effort and attention in acquiring, creating and keeping control of some specific knowledge (Pierce et al. 2001). Psychological ownership influences knowledge hiding (Peng 2013; Serenko and Bontis 2016; Huo et al. 2016; Bhattacharya, 2019) and knowledge hoarding (Anaza and Nowlin 2017). Grant (1996) highlights that the individual who created knowledge has the rights to its ownership and not the organization and individuals consider knowledge as property, as something to be owned as an asset (Nonaka, 1994, Dalkir 2005). This psychological ownership can lead to political gain (Davenport 1997; Ipe 2003), can command obedience (Anand and Walsh, 2016) and improve individual influence in the workplace (Evans et al. 2015). Some, scholars suggest that when people gain unique knowledge about a specific task, they take the ownership of that knowledge to become indispensable and make the organization retain them for the knowledge they own (Pfeffer, 1981). 
Further, people who are encountering job insecurity may attempt to protect their accumulated knowledge and make themselves indispensable to the organization by hiding knowledge. Some people might control this knowledge to become competitors within the same organization (Krakel, 2005). In some instances, people hide knowledge with a sense of ownership to defend their territory (Peng, 2013). For example, when employees have a keen sense of psychological ownership of knowledge, they are more likely to prevent others from accessing their knowledge territory (Brown and Robinson 2007; Huo et al. 2016; Bhattacharya, 2019). Furthermore, when there is an absence of reciprocity for work contribution (Yang, 2004), people develop knowledge ownership and hiding. In addition, ownership to knowledge is prevalent in organizations where individuals feel a lack of respect and competitive threat from managers and co-workers (Pan et al. 2018). On the other hand, Butt and Ahmad (2019) suggested that senior managers hide knowledge from junior employees unless the Top management provides them permission to share.

Proposition 3: Task interdependence leads individuals to hide knowledge by controlling others.

Hostile environment and abusive behaviours (leading to victimized hiding): Threatening environments are settings where people come to suspect that, because of their knowledge, they could be devalued, stigmatized, or discriminated against (Jahanzeb et al. 2019). An employee could resort to knowledge hiding when there is an external threat related to this knowledge, in the form of criticism, harassment, abusive behaviours, intimidation etc. from peers and/or superiors (Zhao and Xia, 2017; Arian et al. 2018; Arain et al. 2019; Riaz et al. 2019). In this case, those who could be the object of this hostility hide their knowledge. Lanke (2018) suggested that, when an employee is 'mistreated' (e.g. interpersonal interaction involving lack of dignity and respect shown toward others) their knowledge hiding behaviour increases (p. 30). Employees perceive their knowledge base to be valuable and the feeling of being 'mistreated or not given due respect' will incline them toward knowledge hiding behaviours (Kim et al. 2016, p. 802). Workplace bullying involves harassing, offending, or socially excluding someone or negatively affecting someone's work. In order for the label bullying (or mobbing) to be applied to a particular activity, interaction, or process like knowledge hiding, the bullying behaviour has to occur repeatedly and regularly (e.g., weekly) and over a period of time (e.g., about six months) (Einarsen et al. 2011, p. 22). Khalid et al (2018) found that abusive supervision is positively 
related to employees' knowledge hiding behaviours. Jha and Varkkey (2018) identified that lack of recognition or lack of reciprocation with subordinates may result in $\mathrm{KH}$.

Proposition 4: Hostility culture and abusive leadership culture leads to hiding knowledge

Social Identity and norms (leading to favoured hiding): Another instance of $\mathrm{KH}$ is when knowledge is linked to individual and/or group identity. Knowledge is then shared within a specific social group. "I favour sharing my knowledge only with groups or people from my region, culture or who share similar values as myself". According to biologist Pagel (2012), there are two distinctive features for people to be affiliated with someone else, groupishness i.e., affiliation with people with whom you share a distinct identity and xenophobia, i.e., demonizing those outside your group and holding parochial views towards themselves. This tends to imply that people may share knowledge only with those people in some social groups with whom they have strong affiliation and hide knowledge from those people with different group affiliations (Bogilović et al. 2017). For example, someone who supports a democrat candidate for president, might be likely to hide her/his knowledge from those who support a republican candidate. Yu and Chu (2007) found that some people fear that their knowledge may become less valuable if they share it with others in a group, and thus choose to withhold it. People will hoard knowledge, unless they feel a strong personal motivation to share it (Reige, 2005). Haas and Park (2010) found that scientists share information only with specific reference groups with which they are either affiliated or share the same norms as themselves. Ethnic prejudice and in- and out-group enmity can induce knowledge hoarding (Khan and Khan 2014). From a national origin perspective, Arian et al. (2019) found that, in a dyadic context, a local company with diverse nationals may face $\mathrm{KH}$ situations where $\mathrm{KH}$ is stronger between a local-foreigner dyad than between a locallocal or foreign-foreign dyad. Similarly, subjective norms in organization can prompt KH (Xiong et al. 2019)

Proposition 5: Social identity and norms in an individual lead to favouring knowledge sharing/hiding among selected groups 


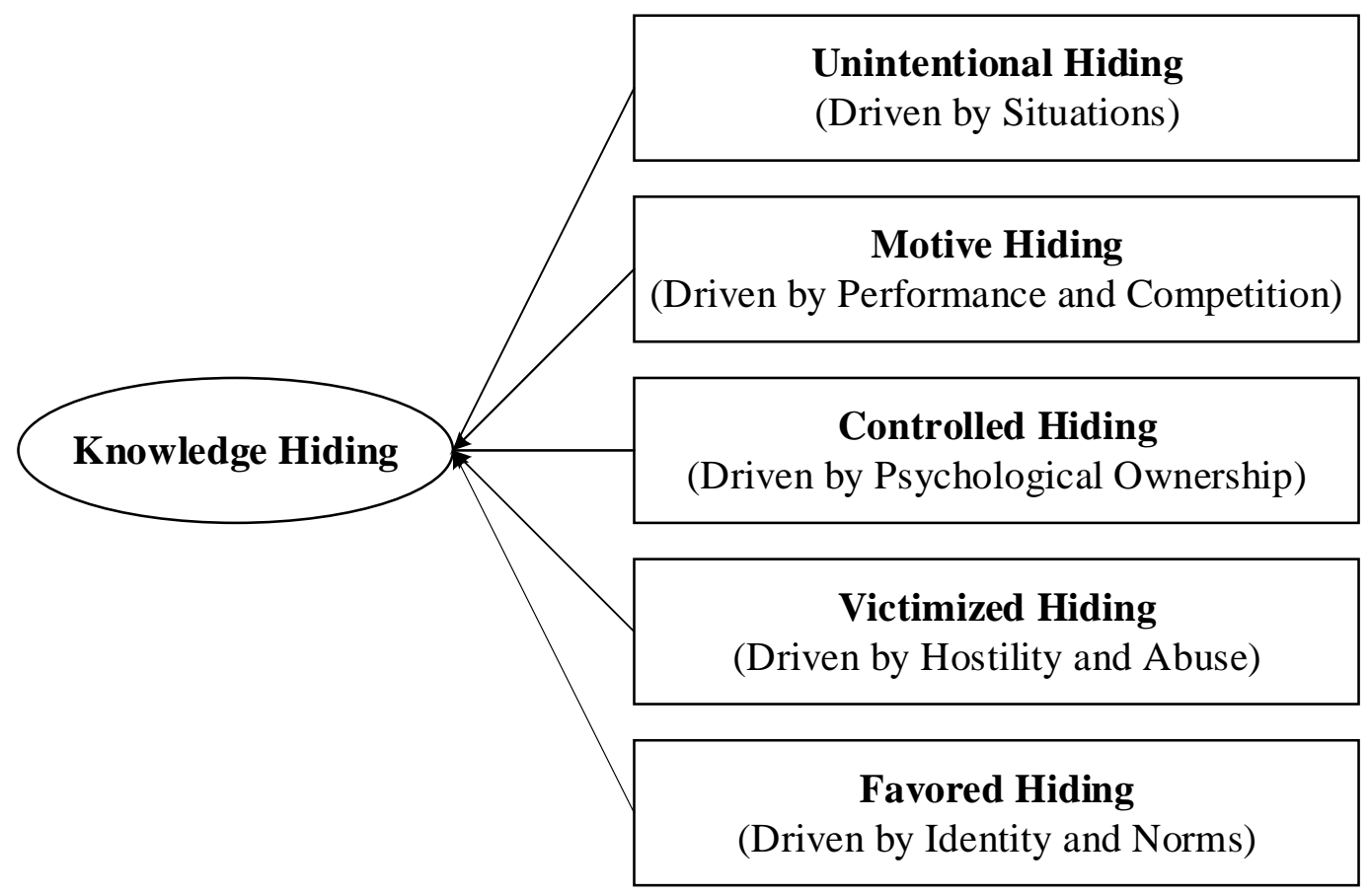

Figure 1. Various events present in the literature leading to Knowledge Hiding among individuals in organizations

\subsection{Possible events of $\mathrm{KH}$ and gaps}

In this section, we provide the various events that may occur in the future with the support from both literature and theory. Although knowledge sharing and knowledge hiding have been mostly studied from a dyadic perspective (e.g. Connelly et al. 2012; Anand et al. 2019), which involves a knowledge seeker and a knowledge provider. The framework proposed in this section corresponds to situations that may arise among individuals in a workplace where hiding, hoarding, or withholding can occur in a dyadic or in a triadic/team network (Figure 2). To our knowledge, these frameworks are new and different from the many possible $\mathrm{KH}$ events investigated in the literature. 


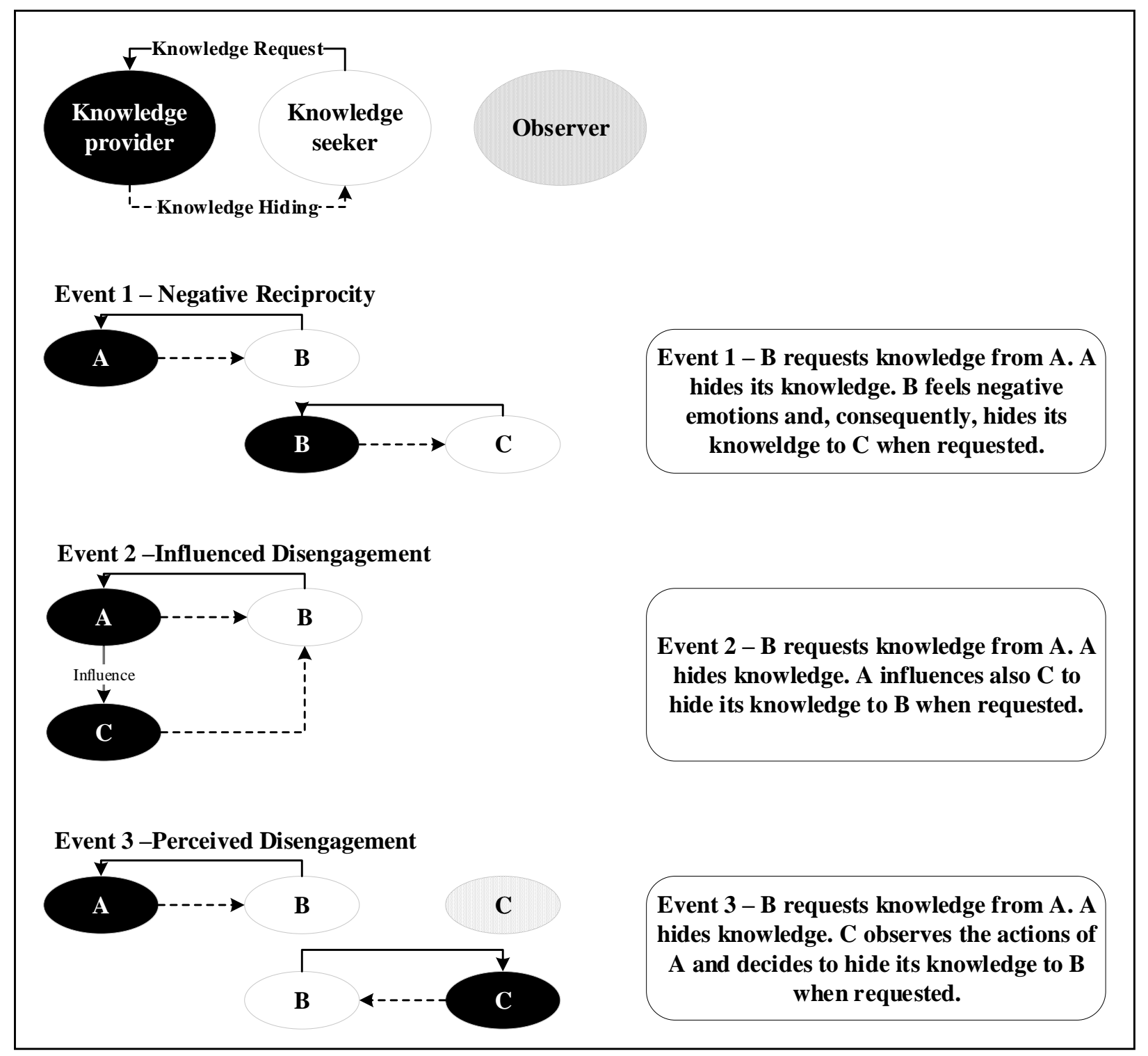

Figure 2. Possible events that may lead to Knowledge Hiding among individuals in organizations

Scenario 1 - Negative Reciprocity: A cost-benefit analysis is often performed by the knowledge hider when deciding on whether to hide a specific piece of knowledge (Xiong et al. 2019). For instance, A (knowledge provider) hides knowledge from B (knowledge seeker), in turn, B develops negative emotions and thus hides knowledge from $\mathrm{C}$. In the above situation, assuming B approaches A for some work-related knowledge and if A is unwilling to share and hides the knowledge, this anticipated perceived effects might reflect on B developing negative emotions and might feel, "Why should I share with others, when others don't share with me" (negative 
reciprocity), and this can lead to counterproductive behaviour, reduced organization citizenship behaviour and low intrinsic motivation (Serenko and Bontis, 2016). In this event, the initial KH of A from B may depend on various events as discussed in section 2. Negative emotions are triggered faster, are processed more thoroughly and are more resistant to change than positive ones. Individuals who have had their previous requests for assistance rebuffed may retaliate by hiding their knowledge (in this case it can be B not sharing with A (Connelly et al. 2012). Hiding is viewed as a lack of trustworthiness that manifests in dislike or avoidance. Anand and Walsh (2016) and Anand et al (2019) explain that people often have feelings like "If I tell them what I know, they won't need me". This makes people hide knowledge because of their fear of losing their position and because of feelings of insecurity. Furthermore, negative co-worker relationships and knowledge recipient disinterest can encourage resistance to sharing knowledge (Nowlin et al. 2015).

Scenario 2 - Influenced Disengagement: A hides knowledge from B, because A may hold differences with B. Also, A presumes that B could seek knowledge from C. Thus, A influences C to hide knowledge from B. This event where one person's hiding behaviour influences another's behaviour may suggest that, for example $\mathrm{C}$ can say, "I think my colleague advising me not to share knowledge with B is right, thus I will also hide my knowledge from B". This event happens if $\mathrm{A}$ and $\mathrm{C}$ have strong interpersonal relations and $\mathrm{C}$ and $\mathrm{B}$ have weak ties or if $\mathrm{C}$ lacks strong intrapersonal character. $\mathrm{C}$ could change behaviour, because of respect for $\mathrm{A}$ or if $\mathrm{A}$ is in a higher hierarchical position. For instance, Lanke (2018) asserted that an interpersonal (in) justice between co-workers along with one holding an expertise power over the other can lead to knowledge hiding behaviour and it is often the case of tacit knowledge (p. 31). Furthermore, assuming A is the leader, Peng et al. (2018) found that self-serving leadership (a form of unethical leadership behaviour that has a destructive effect on its targets and the overall organization) may influence team members to hide knowledge (e.g. from B).

Another instance of influenced disengagement could be on task Interdependence: For instance, knowledge intensive work environments require a frequent exchange of knowledge thus creating interdependence. Task interdependence is the extent to which the work of some depends on the work of others (Gagne et al. 2019). Gagne et al. (2019) suggest that, perceiving that others depend on us to accomplish their work would influence knowledge sharing motivation, increases 
social interactions and also create pressure between co-workers (Singh, 2019). In this case, if C is dependent on A for knowledge, A can alter C's behaviour to hide knowledge from B.

On the other hand, researchers agree that $\mathrm{KH}$ is a goal-directed behaviour (Webster et al. 2008, p. 15; Zhu et al. 2019) and individuals use knowledge as a tool to maximize their advantage. Thus, recent research has suggested that performance-prove goal orientation is a primary individual antecedent of knowledge hiding (Rhee and Choi, 2017). According to Zhu et al. (2019), performance-prove goal orientation drives people to compete against and outperform others and this may prompt knowledge hiding (Rhee and Choi, 2017). In this case A may perceive $\mathrm{B}$ to be competitive and thus to outperform B, A hides knowledge from B and influences $\mathrm{C}$ to hide knowledge from $\mathrm{B}$.

Scenario 3 - Perceived Disengagement: C observes A not sharing with B. C perceives a reciprocal feeling and may hide knowledge from $\mathrm{B}$. In the above situation, $\mathrm{C}$ develops a feeling or imitates the behaviour as observed by A. This unwillingness of A to share with B has a profound and perceived influence on $\mathrm{C}$, thus developing in $\mathrm{C}$ a perceived belief "When others avoid sharing knowledge with B its better I do the same if B asks me”, and thus C hides knowledge from B. In this event, unless C assumes B as a competitive co-worker, these events hold true. We define this event as "perceived disengagement". Here C actions are perceived by observing A's actions. This event may result from playing safe and following others. For instance, members may hide knowledge to avoid being in a tricky situation (Zhao et al. 2016). For example, if a senior employee is found not sharing knowledge with a subordinate (whether senior or junior), this can have an impact on the behaviour of the junior employee who is observing and might follow and behave similarly. Conversely, another situation may arise in which $\mathrm{C}$ observes that A hides knowledge from B. C feels empathy towards B and may share with B. This can be defined as "supportive engagement". De Geofroy and Evans (2017) proposed that high levels of emotional intelligence (i.e., self-awareness, self-management, empathy and relationships management) hinder KH. Some studies go further by suggesting that individuals who find meaning in knowledge will share only the knowledge that reinforces positive perceptions about their identity (Webster et al. 2008; Kang 2014). In the proposed three events, physical proximity between colleagues, lack of trust and communication may lead to knowledge sharing resistance (Qureshi and Evans, 2015; Riege 2005). Conversely, when team members trust one another, 
intentions to withhold knowledge decrease (Lin and Huang 2010). Butt and Ahmad (2019) suggested that lack of personal relationships between employer-employee relationships may lead to top-down knowledge hiding, particularly when the senior manager and their reporting manager come from different cultural backgrounds.

\subsection{Theoretical reflections on events leading to $\mathrm{KH}$}

In this section we identify and propose several theories that may explain the events leading to KH behaviour.

Scenario 1: From an individual perspective of A, who is the key knowledge holder and provider, conservation of resources (COR) theory and social categorization theory (SCT), may explain why knowledge may be hidden (Riaz et al. 2019; Bogilović et al. 2017). According to COR theory individuals strive to obtain, retain, foster, and conserve resources for survival and protect those things they centrally value (Hobfoll et al. 2018 p. 104). In the above three scenarios A may hide knowledge, which may be essential to B and C. Thus, A's behaviour towards hiding knowledge from B can be related to COR. Based on SCT, Bogilović et al. (2017) suggested that an individual (e.g. A) may hide knowledge from others (e.g. B), if they are not from a culturally similar background. Thus, A may intentionally hide knowledge from $\mathrm{B}$, due to cultural differences.

Furthermore, according to psychological ownership theory (Peng, 2013), when individuals feel their knowledge can provide powers to them, they exhibit territorial behaviour to protect their knowledge and command people. Thus, if A possess knowledge, using power behaviour they may protect and hide their knowledge when requested from others (e.g. B). Moreover, according to Gouldner's (1960) research on social exchange theory, individuals also may support a negative norm of reciprocity. When someone perceives rejection when requesting knowledge (e.g. B), they become motivated to retaliate in return by hiding knowledge (e.g. toward C or A) (Connelly \& Zweig, 2014; Khalid et al. 2018; Lanke, 2018). For example, A may hide his/her knowledge from $\mathrm{B}$ and $\mathrm{B}$ may hide in retaliation with $\mathrm{A}$ or maybe from $\mathrm{C}$ when knowledge is requested.

Scenario 2: According to social influence theory (Kelman, 1958), one individual can influence changes in attitude and actions on other individuals, and that changes may occur at various levels. This difference in the level of changes can be attributed to the differences by three 
primary processes of influence: compliance, identification, and internalization. For instance, the influence of compliance is assumed to occur when individuals accept influence and adopt the induced behaviour to gain rewards (or approval) and avoid punishments (or disapproval). Hence, "the satisfaction derived from compliance is due to the social effect of accepting influence from others. Thus, in situation 2, the influence of $\mathrm{A}$ on $\mathrm{C}$ to make $\mathrm{C}$ hide knowledge from $\mathrm{B}$ can be related.

Scenario 3: Offergelt et al. (2019) using social learning theory of Bandura (1978, 1986) suggested that employees look to supervisors as role models and follow them for guidance. The supervisors influence the subordinates to practice and follow. Thus, if $\mathrm{A}$ is assumed to be a leader/supervisor, his/her actions toward hiding knowledge from B as observed by his/her subordinates (e.g. C) may result in C hiding knowledge from B. Additionally, the influence of Internalization from social learning theory is assumed to occur when individuals accept influence after perceiving that the content of the induced behaviour is rewarding in which the content indicates the opinions and actions of others. Therefore, satisfaction occurs due to "the content of the new behaviour". Thus, in situation 3, when C perceives the hiding behaviour of A toward B as a rewarding content, $\mathrm{C}$ may develop similar behaviour towards $\mathrm{B}$ to impress $\mathrm{A}$ or observe and perceive A's action towards B to be right and change his/her existing behaviour of sharing to a new behaviour of hiding from B. Furthermore, according to social learning theory of identification an individual adopts an induced behaviour in order to create or maintain a desired and beneficial relationship to another person or a group. Hence, the satisfaction occurs due to "the act of conforming". This can be related to situation 3 in which $\mathrm{C}$ exhibits behaviour according to group norms (e.g. A's KH behaviour toward B).

\section{Discussion and future implications}

Although a considerable amount of research has been done on knowledge sharing (Wang and Noe, 2010), from this study we found that there has been limited attention paid to KH constructs and this undesirable knowledge behaviour needs more advanced studies (Connelly et al. 2012; Serenko and Bontis, 2016). The evidence from this paper provides a new context and suggests that $\mathrm{KH}$ can be challenging for managers as the existing and proposed events seems to have a negative effect on both the organization and the individual. This study provides an understanding that research on KH only started to emerge in the last 10 years. With many keyword applications 
and searching documents in various databases the limited number of papers demonstrates that the field of $\mathrm{KH}$ is maturing slowly. From this study we found that the concepts of knowledge hiding, withholding, and hoarding have been used interchangeably and researchers have not yet reached a consensus on providing a well operationalized definition of $\mathrm{KH}$. Although in literature the three infamous events proposed by Connelly et al. (2019) best describe KH behaviour, our study contributes, complements and extends beyond these three events by proposing five present events and three possible events that may lead to KH. Since the notion of KH is that there must be a request for knowledge, future research can study the proposed events, for instance, voluntary $\mathrm{KH}$ behaviours (perceived disengagement) among employees and influenced disengagement to others and how this can affect organizations.

Despite managers' investments in facilitating knowledge sharing, knowledge hiding remains prevalent in organizations (Wang et al. 2019) and $\mathrm{KH}$ is found to occur very commonly in organizations and damages interpersonal relations, creativity and innovation (Connelly et al. 2019; Zhu et al. 2019; Jiang et al. 2019; Černe et al. 2014). Furthermore, little empirical research examines KH in organizations (Connelly et al. 2019). Thus, we argue that future studies should pay more attention to the proposed events mentioned and understand the context of $\mathrm{KH}$ from different geographical contexts. Our findings shed light on how managers may prevent such events in organizations and how to facilitate effective sharing among employees. In particular, our research suggests that although research has focused on a dyadic perspective of $\mathrm{KH}$ (Wang et al. 2019; Babic et al. 2019) involving the knowledge seeker and the knowledge provider, the possible dyadic situations presented in this paper that may lead to KH can be empirically tested to study if these events inhibit knowledge hiding and whether they have positive or negative consequences.

The sharing of knowledge is an important part of human resource management, and the HR manager plays a role in ensuring effective knowledge sharing among employees to enhance individual, team and organizational performance (Cabrera and Cabrera, 2005). Understanding the hiding of knowledge, on the other hand, based on the proposed events, may help organizations develop appropriate HR management practices (Xiao and Cooke, 2018; Minbaeva, 2013). Furthermore, future research may investigate how HR practitioners can establish strategies to reduce knowledge hiding behaviour. Lendzion (2015) suggested that human 
resource management should facilitate knowledge sharing which may reduce knowledge hiding behaviour and human resource management strategies should be implemented in organizations to eliminate knowledge hiding behaviour and increase knowledge sharing initiatives (Xiao and Cooke, 2018).

\section{Theoretical Contributions}

Since $\mathrm{KH}$ is a maturing field, more and advanced studies are needed to understand the occurrence and impact of KH. This study in general contributes to knowledge management literature and to the growing literature of $\mathrm{KH}$ specifically and has implications for practitioners. For instance, knowledge sharing is one of the major goals of the organizational knowledge management system through which an organization facilitates the transfer of knowledge among its members (Youssef et al. 2017; Arian et al. 2019) and on the other hand, employee knowledge sharing behaviour helps organizations to sustain their competitive advantage and plays a unique role in the process of knowledge management (Butt and Ahmad, 2019). Furthermore, knowledge sharing, and knowledge hiding can adversely affect the knowledge management process of firms (Arian et al. 2019; Butt and Ahmad, 2019). Scholars seeking to advance on identifying and extending $\mathrm{KH}$ in various events can find this article a progressive contribution to future research and theory building. For instance, theories such as conservation of resources, social exchange theory, psychological ownership theory and social influence theory may help researchers to further test theory with data, which can develop new debates and findings on KH. The research findings would provide scholars with a comprehensive framework to examine $\mathrm{KH}$ at an individual, group and organizational level. Scholars can explore how to reduce such impeding factors in the workplace that cause KH. More elaborative studies and empirical in-depth examination on the proposed framework are needed. The research outcomes could then be used in developing measurement models with scales within organization. Besides the framework proposed, the potential moderators that may offset the effect of $\mathrm{KH}$ can provide scholars with a broader understanding of reducing KH effects. For instance, perceived organizational culture and fair competition (Xiong et al. 2019; Anand et al. 2019) may reduce the KH in proposed events.

Some literature posits that sharing should not be encouraged (Husted and Michailova, 2002) and withholding is good for organizations (Krakel, 2005). Hence, future research can study the 
positive and negative effects of $\mathrm{KH}$ through the proposed events. Researchers should now focus more studies on the benefits or advantages of $\mathrm{KH}$, as many studies portray $\mathrm{KH}$ as a negative construct. Further, the proposed events may vary according to the size of the industry (e.g. micro, large, family, small or public industries), and type of industry (e.g. hospitality, IT, retail). Hence future research can better understand this phenomenon in different contexts. Most literature involves the presence of a knowledge seeker and knowledge provider. However, the presence of an observer in this event can be helpful for future research to study whether KH between two people can influence a third person who is observing. Thus, as proposed in the framework, research must investigate the perspective of the seeker, provider and observer. Although research on knowledge sharing and knowledge hiding has been studied mostly from a dyadic perspective (e.g. Babic et al. 2019; Anand et al. 2019; Zhang and Jiang, 2015; Connelly et al. 2012) involving a seeker and a provider, our research of having an observer in a triadic network could provide results that can help managers prevent the proposed knowledge hiding events. Future research can study $\mathrm{KH}$ activities from a gender and intergenerational perspective, since no studies have explicitly provided evidence on whether male, female, older to younger employees have varying degrees of KH. Furthermore, differences in work experiences, hierarchy levels between male and female having any impact on hiding behaviour can be explored.

Researchers could also explore whether any moderating effects like trust, relationship, social capital, support, climate etc. may offset such events of KH. For instance, religious beliefs and practice suggest that hiding knowledge is a sin (Naachimuthu, 2007; Mababaya, 2005). This religiosity as moderator can help understand $\mathrm{KH}$ reducing in proposed events. Since our literature review is theoretical, we suggest that how hiding behaviours can occur under different situations needs to be understood in a broader literature review, for example, the process of engendering knowledge hiding within specific situation (as proposed in our framework) remains unknown (Connelly et al. 2012). Lastly, whether such events force organizations to adopt change or restructure their discourse of culture, process and strategies needs more investigation. For instance, when an organization undergoes change, whether these events diminish or still exist. 


\section{Conclusion}

The aim of this study was to explore the various events that may lead to $\mathrm{KH}$ behaviour among employees. We identified six broad categories of events that lead to $\mathrm{KH}$ : driven by situation, which explains the reason for unintentional hiding; driven by performance and competition, which leads individuals to justify hiding knowledge; driven by psychological ownership, which leads to controlled hiding; driven by hostility and abuse by employees or managers, which leads to victimized hiding; and lastly, driven by identity and norms which, leads to favoured hiding. Furthermore, in this study, we uncovered three potential future events which need managerial attention: negative reciprocity, influenced disengagement, and perceived disengagement. Our study provided theoretical contributions resulting in a research agenda. Thus, we conclude that this paper offers new insights to managers to understand the present events and foresee the possible reasons for $\mathrm{KH}$ behaviour and how can they can strategize to reduce these events and undergo organizational change. This paper also offers new insights to managers to understand the present and to foresee the possible future events leading to $\mathrm{KH}$ behaviour and how can they can strategize to reduce these events.

\section{Limitations}

Although knowledge can be shared or withheld on both an individual (i.e. between colleagues) and an organizational (i.e. between companies) level, the main limitation of our approach is that we confine our understanding of the knowledge hiding perspective to a literature reviewed method. Our study fails to provide a broader view on knowledge hiding as, despite growing attention in this field, very few studies have been conducted so far. Thus, follow-up studies should adopt a broader scope, investigating knowledge hiding between members and organizations through citation trends or a bibliometric analysis to reach a more comprehensive and balanced understanding of knowledge hiding. On the other hand, some overlapping concepts such as knowledge sharing hostility, knowledge sharing disengagement, knowledge obstruction, knowledge hindrance, and knowledge withholding may have limited our search of broadening the scope of our events. 


\section{References}

Anand P, Jain K. K. (2014). Big Five personality types and knowledge hiding behaviour: A theoretical framework. Archives of Business Research 2(5), 47-56.

Anand, A. and Walsh, I., (2016). Should knowledge be shared generously? Tracing insights from past to present and describing a framework. Journal of Knowledge Management 20(4). 
Anand, A., Walsh, I. and Moffett, S. (2019), "Does humility facilitate knowledge sharing? Investigating the role of humble knowledge inquiry and response", Journal of Knowledge Management, 23(6) pp. 1218-1244.

Anand, P. and Hassan, Y. (2019), "Knowledge hiding in organizations: everything that managers need to know", Development and Learning in Organizations. ahead-of-print.

Anaza, N. A. and Nowlin, E. L. (2017). What's mine is mine: A study of salesperson knowledge withholding and hoarding behavior. Industrial Marketing Management 64, 14-24.

Arain, G.A., Bhatti, Z.A., Ashraf, N. and Fang, Y.-H. (2018), "Top-Down knowledge hiding in organizations: an empirical study of the consequences of supervisor knowledge hiding among local and foreign workers in the Middle east", Journal of Business Ethics, pp. 1-15.

Arain, G.A., Bhatti, Z.A., Hameed I, and Fang, Y.-H. (2019), “Top-down knowledge hiding and innovative work behavior (IWB): a three-way moderated-mediation analysis of self-efficacy and local/foreign status”, Journal of Knowledge Management, pp. 1-15.

Arshad, R. and Ismail, I. R. (2018). Workplace incivility and knowledge hiding behavior: Does personality matter? Journal of Organizational Effectiveness: People and Performance 5(3), 278288.

Aslam, U., Muqadas, F., Imran, M. K., Saboor, A., and Saboor, A. (2018). Emerging organizational parameters and their roles in implementation of organizational change parameters. Journal of Organizational Change Management.

Babič, K., Černe, M., Connelly, C., Dysvik, A. and Škerlavaj, M. (2019), "Are we in this together? Knowledge hiding in teams, collective prosocial motivation and leader-member exchange", Journal of Knowledge Management, Vol. ahead-of-print No. ahead-ofprint. https://doi.org/10.1108/JKM-12-2018-0734.

Bandura, A. (1978). Social learning theory of aggression. Journal of communication, 28(3), 12-29.

Bandura, A. (1986). Social foundations of thought and action. Englewood Cliffs, NJ, 1986.

Bari, M.W., Abrar, M., Shaheen, S., Bashir, M. and Fanchen, M., (2019). Knowledge Hiding Behaviors and Team Creativity: The Contingent Role of Perceived Mastery Motivational Climate. SAGE Open, 9(3). 
Bhattacharya (2019) Dilemma Between 'It's My or It's My Organization's Territory': Antecedent to Knowledge Hiding in Indian Knowledge Base Industry. International Journal of Knowledge Management (IJKM) 15(3), p. 1-21

Burmeister, A., Fasbender, U. and Gerpott, F. H. (2018). Consequences of knowledge hiding: The differential compensatory effects of guilt and shame. Journal of Knowledge Management Studies 12249.

Butt, A. and Ahmad, A. (2019), "Are there any antecedents of top-down knowledge hiding in firms? Evidence from the United Arab Emirates", Journal of Knowledge Management, Vol. aheadof-print No. ahead-of-print.

Bock, G. W., Zmud, R. W., Kim, Y. G. and Lee, J. N. (2005). Behavioral intention formation in knowledge sharing: Examining the roles of extrinsic motivators, social-psychological forces, and organizational climate. MIS Quarterly 29(1), 87-111

Bogilović, S., Černe, M., \& Škerlavaj, M. (2017). Hiding behind a mask? Cultural intelligence, knowledge hiding, and individual and team creativity. European Journal of Work and Organizational Psychology, 26(5), 710-723.

Cabrera, A. and Cabrera, E. F. (2002). Knowledge-sharing dilemmas. Organization Studies 23, 687710.

Cabrera, E.F. and Cabrera, A. (2005). 'Fostering knowledge sharing through people management practices'. International Journal of Human Resource Management, vol. 16, nº 5, pp. 720735.

Cerne, M., Nerstad, C. G. L., Dysvik, A. and Škerlavaj, M. (2014). What goes around comes around: Knowledge hiding, motivational climate, and creativity. Academy of Management Journal 57(1), 172-192.

Černe, M., Hernaus, T., Dysvik, A., Škerlavaj, M. (2017). The role of multilevel synergistic interplay among team mastery climate, knowledge hiding, and job characteristics in stimulating innovative work behavior. Human Resource Management Journal, 27, 281-299.

Connelly, C. E. and Zweig, D., (2014). How perpetrators and targets construe knowledge hiding in organizations. European Journal of Work and Organizational Psychology 24(3), 479-489. 
Connelly, C. E., Zweig, D., Webster, J. and Trougakos, J. P. (2012). Knowledge hiding in organizations. Journal of Organizational Behavior 33(1), 64-88.

Chennamaneni, A., Teng, J. T. C., and Raja, M. K. (2012). A unified framework of knowledge sharing behaviours: theoretical development and empirical test. Behaviour and Information Technology, 31(11), 1097-1115.

de Geofroy, Z. and Evans, M. M. (2017). Are emotionally intelligent employees less likely to hide their knowledge? Knowledge and Process Management 24(2), 81-95

Dalkir, K. (2005), Knowledge Management in Theory and Practice, Elsevier ButterworthHeinemann, Oxford

Demirkasımoğlu, N. (2016). Knowledge hiding in academia: Is personality a key factor? International Journal of Higher Education, 5(1), 128-140.

Dong, Y., Bartol, K.M., Zhang, Z.X. and Li, C. (2017), "Enhancing employee creativity via individual skill development and team knowledge sharing: influences of dual-focused transformational leadership", Journal of Organizational Behavior, Vol. 38 No. 3, pp. 439-458.

Einarsen, S., Hoel, H., Zapf, D. and Cooper, C.L. (2011), "The concept of bullying and harassment at work: the European tradition", in Einarsen, S., Hoel, H., Zapf, D. and Cooper, C.L. ( Eds), Bullying and Harassment in the Workplace: Developments in Theory, Research, and Practice, Taylor and Francis Group, Boca Raton, pp. 3-40

Engle, C. and Engle, N. (2010). The 2020 federal knowledge worker. VINE: The Journal of Information and Knowledge Management Systems 40, 277-286.

Evans, J. M., Hendron, M. G. and Oldroyd, J. B. (2014). Withholding the ace: The Individual- and unit-level performance effects of self-reported and perceived knowledge hoarding. Organization Science 26(2), 494-510.

Ferrari, R. (2015). Writing narrative style literature reviews. The European Medical Writers Association 24(4), 230-235 
Fong, P. S. W., Men, C., Luo, J. and Jia, R. (2018). Knowledge hiding and team creativity: The contingent role of task interdependence. Management Decision 56(2), 329-343.

Gardiner, C.M. (2016). Knowledge sharing success and resistance in an engineering department: A case study. Journal of Management and Organization 22(2), 254-271.

Gouldner, A. W. (1960). The norm of reciprocity: A preliminary statement. American sociological review, 161-178.

Green, B. N., Johnson, C. D., Adams, A. (2006). Writing narrative literature reviews for peerreviewed journals: Secrets of the trade. Journal of Chiropractic Medicine 5(3), 101-117.

Grant, R. M. (1996). Toward a knowledge-based view of the firm. Strategic Management Journal.

Haas, M. R. and Park, S. (2010). To share or not to share? Professional norms, reference groups, and information withholding among life scientists. Organization Science, 21(4), 873-891.

Hernaus, T., Cerne, M., Connelly, C., Vokic, N. P., Škerlavaj, M., Hernaus, T., ... Miha, Š. (2018). Evasive knowledge hiding in academia: when competitive individuals are asked to collaborate. Journal of Knowledge Management, In press.

Holten, A.-L., Hancock G. R, Persson, R., Hansen A.M. and Høgh A. (2016). Knowledge hoarding: Antecedent or consequent of negative acts? The mediating role of trust and justice. Journal of Knowledge Management 20(2), 215-229.

Hobfoll, S. E., Halbesleben, J., Neveu, J. P., and Westman, M. (2018). Conservation of resources in the organizational context: The reality of resources and their consequences. Annual Review of Organizational Psychology and Organizational Behavior, 5, 103-128.

Huo, W., Cai, Z., Luo, J., Men, C. and Jia, R. (2016). Antecedents and intervention mechanisms: A multi-level study of RandD team's knowledge hiding behavior. Journal of Knowledge Management 20(5), 880-897.

Husted, K. and Michailova, S. (2002). Diagnosing and fighting knowledge-sharing hostility. Organizational Dynamics 31(1), 60-73. 
Jha, K. J. and Varkkey, B. (2018). Are you a cistern or a channel? Exploring factors triggering knowledge-hiding behavior at the workplace: Evidence from the Indian RandD professionals. Journal of Knowledge Management 22(4), 824-849.

Kang, S.-W. (2014). Knowledge withholding: Psychological hindrance to the innovation diffusion within an organization. Knowledge Management Research and Practice 14(1), 144-149.

Khalid, M., Bashir, S., Khan, A.K. and Abbas, A. (2018). When and how abusive supervision leads to knowledge hiding behaviors: An Islamic work ethics perspective. Leadership and Organization Development Journal 39(6), 794-806.

Kelman, H. C. (1958). Compliance, identification, and internalization three processes of attitude change. Journal of conflict resolution, 2(1), 51-60.

Khan, S. R. and Khan, I. A. (2014). Understanding ethnicity and national culture: A theoretical perspective on knowledge management in the organization. Knowledge and Process Management 22(1), 51-61.

Kim, S. L., Lee, S., and Yun, S. (2016). Abusive supervision, knowledge sharing, and individual factors. Journal of Managerial Psychology, 31(6), 1106-1120.

Kube, S., Maréchal, M.A. and Puppe, C. (2013), "Do wage cuts damage work morale? Evidence from a natural field experiment", Journal ofthe European Economic Association, Vol. 11 No. 4, pp. $853-870$

Kräkel, M. (2005). On the benefits of withholding knowledge in organizations. International Journal of the Economics of Business 12(2), 193-209.

Ladan, S., Nordin, N. B., and Belal, H. M. (2017). Does knowledge based psychological ownership matter? Transformational leadership and knowledge hiding: A proposed framework. Journal of Business and Retail Management Research, 11(4), 60-67

Lanke, P. (2018). Knowledge hiding: Impact of interpersonal behavior and expertise. Human Resource Management International Digest 26(2), 30-32

Lendzion J.P. (2015), Human Resources Management in the System of Organizational Knowledge Management/Procedia Manufacturing, 3, pp. 674-680 
Liao, Q. Q., Qin, Y. J. and Zhang, X. (2011). Relationship between psychological knowledge ownership and knowledge sharing: Adjustment for organizational fairness. Proceedings of the 8th International Conference on Innovation and Management (pp. 916-920).

Mababaya, N.B.M.D. (2005), "Introduction to Islam", available at: www.wisdom.edu.ph/INTRODUCTION_TO_ISLAM-WISHES-EBOOK.pdf (accessed 20 February 2019).

Malik, P. Garg. P (2017). The relationship between learning culture, inquiry and dialogue, knowledge sharing structure and affective commitment to change. Journal of Organizational Change Management, 30(4), 610-631.

Mergel, I., Lazer, D. and Binz-Scharf, M. C. (2008). Lending a helping hand: Voluntary engagement in knowledge sharing. International Journal of Learning and Change 3(1), 5-22.

Milne, P. (2007). Motivation, incentives and organizational culture. Journal of Knowledge Management 11(6), 28-38.

Minbaeva D (2013) Strategic HRM in building micro-foundations of organizational knowledgebased performance. Human Resource Management Review 23(4), 378 -3907.

Muqadas, F., Rehman, M., Aslam, U. and Ur-Rahman, U. (2017). Exploring the challenges, trends and issues for knowledge sharing: A study on employees in public sector universities. VINE Journal of Information and Knowledge Management Systems 47(1), 2-15.

Naachimuthu, K.P. (2007), "We are from knowledge sharing culture”, Journal of Management and Labour Studies, Vol. 32 No. 3.

Nissen, M. E. (2002). An extended framework of knowledge-flow dynamics. Communications of the Association for Information Systems 8(1), 251-266.

Nowlin, E. L., Anaza, N. A., Anaza, E. and Nowlin, E. L. (2015). Salesperson resistance to sharing market intelligence in Sub-Saharan Africa. Journal of Marketing Channels 22(2), 93-107.

Nonaka, I. (1994). A Dynamic Theory of Organizational Knowledge Creation Dynamic Theory Knowledge of Organizational Creation. Organization Science, 5(1), 14-37.

Nugroho, M. A. (2018). The effects of collaborative cultures and knowledge sharing on organizational learning. Journal of Organizational Change Management. https://doi.org/10.1108/JOCM-10-2017-0385 
Ott, D. L., and Michailova, S. (2018). Cultural Intelligence: A Review and New Research Avenues. International Journal of Management Reviews, 20(1), 99-119.

Offergelt, F., Spörrle, M., Moser, K., \& Shaw, J. D (2019). Leader-signaled knowledge hiding: Effects on employees' job attitudes and empowerment. Journal of Organizational Behavior (in press).

Pagel, M. (2012). Languages evolved to prevent us communicating. University of Reading, available at: www.reading.ac.uk/news-and-events/releases/ PR478283.aspx

Pan, W. and Zhang, Q. (2018). Withholding knowledge in teams: An interactionist perspective of personality, justice and autonomy 46(12), 1-16.

Pan, W., Zhang, Q., Teo, T. S. H. and Lim, V. K. G. (2018). The dark triad and knowledge hiding. International Journal of Information Management 42(March), 36-48.

Pan, W., Zhou, Y. and Zhang, Q. (2016). Does darker hide more knowledge? The relationship between Machiavellianism and knowledge hiding. International Journal of Security and Its Applications 10(11), 281-292.

Pierce JL, T Kostova and KT Dirks (2001) Toward a theory of psychological ownership in organisations. Academy of Management Review 26(2), 298-310

Peng, H. (2013). Why and when do people hide knowledge? Journal of Knowledge Management 17(3), 398-415.

Pfeffer, J. (1981). Power in organizations. Pitman, Marshfield, MA.

Qureshi, A. M. A. and Evans, N. (2015). Deterrents to knowledge-sharing in the pharmaceutical industry: A case study. Journal of Knowledge Management, 19(2), 296-314.

Riege, A. (2005). Three-dozen knowledge-sharing barriers managers must consider. Journal of Knowledge Management 9(3), 18-35.

Riaz S. Xu Y and Hussain S (2019). Workplace Ostracism and Knowledge Hiding: The Mediating Role of Job Tension, Sustainability, 11, (5547) P. 1-16

Semerci. (2018). Examination of knowledge hiding with conflict, competition and personal values. International Journal of Conflict Management, 30(1), 111-131. 
Serenko, A. and Bontis, N., (2016). Understanding counterproductive knowledge behavior: Antecedents and consequences of intra-organizational knowledge hiding. Journal of Knowledge Management 20(6), 1199-1224.

Singh, S. K. (2019). Territoriality, task performance, and workplace deviance: Empirical evidence on role of knowledge hiding. Journal of Business Research, 97, 10-19.

Skerlavaj, M., Connelly, C. E., Cerne, M. and Dysvik, A. (2018). Tell me if you can: Time pressure, prosocial motivation, perspective taking, and knowledge hiding. Journal of Knowledge Management. 22(7).1489-1509

Snilstveit B, Oliver S, Vojtkova M (2012) Narrative approaches to systematic review and synthesis of evidence for international development policy and practice. Journal of Development Effectiveness 4:409-429

Spivey, M. (2010). Coping With Minority Status: Responses to Exclusion and Inclusion. Journal of Social Work Values and Ethics, 7(2), 2009-2010.

Sun, Y., Shen, X. and Wang, N., (2015). Knowledge Withholding in Online Brand Community: A Neutralization Perspective. Icis, pp.1-17.

Tsay, C.H.H. Lin, T. C., Yoon, J., and Huang, C. C., (2014). Knowledge withholding intentions in teams: The roles of normative conformity, affective bonding, rational choice and social cognition. Decision Support Systems, 67, pp.53-58.

Xia, Q., Yan, S., Zhang, Y. and Chen, B. (2019), "The curvilinear relationship between knowledge leadership and knowledge hiding", Leadership and Organization Development Journal, Vol. 40 No. 6, pp. 669-683.

Xiao, M., and Cooke, F. L. (2018). Why and when knowledge hiding in the workplace is harmful : a review of the literature and directions for future research in the Chinese context, Asia Pacific Journal of Human Resources.

Youssef, M., Saheem, W. and Youssef, E.M. (2017), “A structural equation model of knowledge sharing behavior in an emerging economy”, Journal of Knowledge Management, Vol. 21 No. 4, pp. $925-945$ 
Wang, S., and Noe, R. a. (2010). Knowledge sharing: A review and directions for future research.

Human Resource Management Review, 20(2), 115-131.

Webster, J., Brown, G., Zweig, D., Connelly, C., Brodt, S. and Sitkin, S. (2008). Beyond knowledge sharing: Knowledge hiding and hoarding at work. In J. J. Martocchio (ed.), Research in personnel and human resources management, volume 27, (pp.1-37). Emerald Publishing Limited.

Zhao, H. and Xia, Q. (2017). An examination of the curvilinear relationship between workplace ostracism and knowledge hoarding. Management Decision 55(2), 331-346.

Zhao, H., He, P., Sheard, G. and Wan, P. (2016). Workplace ostracism and knowledge hiding in service organizations. International Journal of Hospitality Management 59, 84-94.

Zhu, Y., Chen, T., Wang, M., Jin, Y., and Wang, Y. (2019). Rivals or allies: How performance-prove goal orientation influences knowledge hiding. Journal of Organizational Behavior, 40(7), 849-868.

Appendix -1 - List of articles adopted for review.

\begin{tabular}{|c|c|c|}
\hline Authors & $\begin{array}{c}\text { Scopus } \\
\text { Database }\end{array}$ & $\begin{array}{c}\text { Other Databases (Google } \\
\text { Scholar, EBSCO, Proquest) }\end{array}$ \\
\hline Anand and Hassan (2019) & & $\sqrt{ }$ \\
\hline Anand and Jain (2014) & & $\sqrt{ }$ \\
\hline Anaza and Nowlin (2017) & $\sqrt{ }$ \\
\hline Arain et al (2019) & $\sqrt{ }$ & \\
\hline Arian et al (2018) & & \\
\hline Babič et al, (2019) & $\sqrt{ }$ & \\
\hline Bhattacharya (2019) & $\sqrt{ }$ & \\
\hline Bogilović et al. (2017) & $\sqrt{ }$ & \\
\hline Butt and Ahmad (2019) & $\sqrt{ }$ & \\
\hline Cerne et al. (2014) & & \\
\hline
\end{tabular}




\begin{tabular}{|c|c|c|}
\hline Cerne et al. (2017) & $\sqrt{ }$ & \\
\hline Connelly and Zweig (2014) & $\sqrt{ }$ & \\
\hline Connelly et al. (2019) & $\sqrt{ }$ & \\
\hline Connelly et al. (2012) & $\sqrt{ }$ & \\
\hline de Geofroy and Evans (2017) & & $\mathrm{v}$ \\
\hline Demirkasimoglu (2015) & & $\sqrt{ }$ \\
\hline Evans et al. (2014) & $\sqrt{ }$ & \\
\hline Fong et al. (2018) & $\sqrt{ }$ & \\
\hline Gardiner (2016) & & $\sqrt{ }$ \\
\hline Haas and Park (2010) & $\sqrt{ }$ & \\
\hline Hernaus et al (2019) & $\sqrt{ }$ & \\
\hline Huo et al. (2016) & $\sqrt{ }$ & \\
\hline Jahanzeb et al (2019) & $\sqrt{ }$ & \\
\hline Jha and Varkkey (2018) & $\sqrt{ }$ & \\
\hline Jiang et al (2019) & $\sqrt{ }$ & \\
\hline Kang (2014) & $\sqrt{ }$ & \\
\hline Khalid et al. (2018) & $\sqrt{ }$ & \\
\hline Khan and Khan (2014) & $\sqrt{ }$ & \\
\hline Kräkel (2005) & $\sqrt{ }$ & \\
\hline \multicolumn{3}{|l|}{ Lanke (2018) } \\
\hline Lin and Huang (2010) & . & $\sqrt{ }$ \\
\hline \multicolumn{3}{|l|}{ Muqadas et al. (2017) } \\
\hline Nowlin et al. (2015) & $\sqrt{ }$ & \\
\hline Offergelt et al. (2019) & & $\sqrt{ }$ \\
\hline Pan et al. (2016) & $\sqrt{ }$ & \\
\hline Pan et al. (2018) & $\sqrt{ }$ & \\
\hline Peng (2013) & $\sqrt{ }$ & \\
\hline Peng et al. (2018) & $\sqrt{ }$ & \\
\hline Qureshi and Evans (2015) & $\sqrt{ }$ & \\
\hline Rhee and Choi (2016) & & $\sqrt{ }$ \\
\hline Riaz et al (2019) & & $\sqrt{ }$ \\
\hline Riege (2005) & $\sqrt{ }$ & \\
\hline Samerci (2019) & $\sqrt{ }$ & \\
\hline Serenko and Bontis (2016) & $\sqrt{ }$ & \\
\hline Singh, (2019) & $\sqrt{ }$ & \\
\hline Skerlavaj et al. (2018) & $\sqrt{ }$ & \\
\hline Tsay et al. (2014) & & $\sqrt{ }$ \\
\hline Webster et al. (2008) & & $\sqrt{ }$ \\
\hline Xia et al (2019) & $\sqrt{ }$ & \\
\hline Xio and Cooke, 2018 & $\sqrt{ }$ & \\
\hline Xiong et al (2019) & $\sqrt{ }$ & \\
\hline
\end{tabular}


Zhao et al. (2016)

Zhu et al (2019) 